\title{
Remarques sur le mécanisme du sacrifice Dogon (Soudan français)
}

Comments on the mechanism of Dogon sacrifice (French Sudan)

\section{Marcel Griaule}

\section{(2) OpenEdition}

1 Journals

Édition électronique

URL : http://journals.openedition.org/span/293

DOI : $10.4000 /$ span.293

ISSN : 2268-1558

Éditeur

École pratique des hautes études. Sciences humaines

\section{Édition imprimée}

Date de publication : 1 septembre 1976

Pagination : 51-54

ISSN : 0294-7080

\section{Référence électronique}

Marcel Griaule, "Remarques sur le mécanisme du sacrifice Dogon (Soudan français) », Systèmes de pensée en Afrique noire [En ligne], 2 | 1976, mis en ligne le 04 juin 2013, consulté le 19 avril 2019. URL http://journals.openedition.org/span/293; DOI : 10.4000/span.293 
Annexe
R E M A R Q E S
$S$ U R
L E
MÉ C A N I S M E
D U
S A C R I F I C E
D O GON
(SOU D A N
F R A N C A I S)
par
Marcel Griaule

Les Dogons conçoivent le sacrifice comme un moyen pour les hommes de se mettre en communication avec les puissances surnaturelles. Ils lui ont donné de multiples formes allant de la simple libation à l'immolation d'animaux (et anciennement d'êtres humains) suivie de consommation. A ces formes correspondent des buts très divers; le sacrifice est 1 'acte central de nombreux rites pratiqués dans le culte des morts ou dans le service ordinaire des puissances, à des fins de purification, de consecration, de divination, de propitiation entre autres.

Pourtant, sous ces apparences variées, le sacrifice, chez les Dogons, a un effet constant qui est d'actionner le nyama des êtres en cause dans un sens voulu par l'homme (1). Le nyama est "une ënergie en instance, impersonnelle, inconsciente, répartie dans tous les animaux, végétaux, dans les êtres surnaturels, dans les choses de la nature et qui tend à faire persêvérer dans son être le support auquel elle est affectée temporairement (être mortel) ou éternellement (être immortel)" (2). Il est mû par la volontê intelligente du kindu kindu,

(1) Ce sont les différents sens imprimés à cette action qui donnent les divers aspects du sacrifice.

(2) Cf. M. GRIAUle, Masques Dogons, Travaux et Mémoires de 1'Institut d'ethnologie de I'Université de Paris, T. XXXIII, p. 160 et ss. En ce qui concerne l'affectation éternelle, elle est cependant subordonnée, dans 1'idée des Dogons, à la régularité du culte rendu au porteur. 
âme, "je" de l'individu et n'est autre que sa personnalité, son "moi" (3).

Une des principales caractéristiques du nyama, force et essence, pouvoir physique et spirituel, est dẻcelée et utilisée dans le sacrifice : il est, en effet, divisible et transmissible, tout particulièrement lors de la disparition de son support, c'est-à-dire au moment de la mort physique. Ainsi, en ce qui concerne les hommes, après la mort, le nyama se partage entre plusieurs répondants (nani), désignés par l'âme du dêfunt parmi ses descendants nouveaux-nés ou simplement conçus. Lorsque la mort est anormale (meurtre, guerre, par exemple), le nyoma du défunt, dirigé par l'âme, s'attaque au meurtrier ou à l'un de ses descendants. Dans le cas de mort sacrificielle, la force est dirigée par l'agent seIon un mécanisme qui apparaît clairement dans le service ordinaire d'une puissance surnaturelle. En cette occasion les données sont les suivantes (cf. fig. 38) :

S -- le sacrifiant (agent)

$\mathrm{V}$-- la victime (dêclancheur)

A -- 1'autel (accumulateur)

$P$-- 1a puissance

Au moment critique de l'acte, c'est-à-dire au moment de l'égorgement de la victime, les contacts suivants sont établis quasi simultanêment entre les différents êtres mis en cause :

1a force vitale, nyama, du sacrifiant, portée par sa prière, alerte la puissance $P$ (trajet 1);

le nycma de la victime, canalisé dans le sang, passe dans l'aute1 (4) (trajet 2);

1a puissance envoie son nyama dans A (trajet 3) et y puise ellemême une nouvelle force; $P$ est à la fois nourrie et nourrissante (5);

(3) La personnalité est un composé de divers nyama, cf. G. DIETERLEN. Les Ames des Dogons, Travaux et Mémoires de l'Institut d'Ethnologie, tome XL, Chap. II, La Personnalité.

(4) Les informateurs déclarent que "l'autel boit le sang de la victime comme un enfant tète sa mère".

(5) Voir la note précédente. Il est à remarquer que le mot buzu, qui désigne tout sacrifice sanglant, a le sens de "faire revivre". Cf. S. DE GANAY, Les Dogons. Le Totem Yébéné, Miscellanea Africana Le baudy, cahier 2 (à paraître). 
Remarques sur le mêcanisme du sacrifice dogon

la force de 1'autel (6) alimentêe par ce passage, remonte dans la victime et tout spécialement dans son foie (trajet 5);

le sacrifiant consomme le foie et assimile la force qu'il contient (trajet 6).

Le circuit est ainsi fermé. Il est fait de canaux visibles ou audibles : parole, sang, bol alimentaire (côté humain) et de canaux invisibles : trajet PA, AP, AV (côtê surhumain). Dans ce dernier cas, le nyama est à la fois le véhicule et le véhiculé, le conduit et ce qui est conduit.

Ce circuit, dans son ensemble, intéresse des forces qu'il ne crée point et qu'aucun cles relais ( $A, P, S, V$ ) ne crêe. Le sacrifice n'est pas action crêatrice; tous les actes oraux et manuels de ses agents n'ont d'autre efficacité que de conduire vers un but et selon un circuit voulus une vertu préexistant radicalement dans les êtres et matières mêmes qu'ils utilisent ou supposent. Le sacrifice serait sans objet, nonobstant toute science de procédure, s'il en était autrement.

Le sacrifice n'est pas non plus action destructrice. Il est utilisation complète d'une force mise à disposition par séparation de son support.

Le sacrifice n'étant ni création ni destruction, son efficacité réside dans le mouvement de forces qu'il provoque, à l'intêrieur d'un circuit utile, par déclanchement en un secteur (SVA) contrôlé par le sacrifiant. Ce déclancheur est la mort provoquée de la victime, libëratrice d'une force dont l'êlan incite au mouvement d'autres forces qui, par leurs réactions et leurs échanges, profitent au sacrifiant et à la puissance surraturelle.

Le sacrifice, chez les Dogons, est donc, dans sa partie centrale, un acte téchnique dêterminant un déplacement de nyoma et compris comme tel.

(6) L'autel est le carrefour puissance-victime et, par suite, puissance-sacrifiant. Il est aussi le réservoir où boit la puissance, où puise le sacrifiant. Il représente, de plus, la puissance.

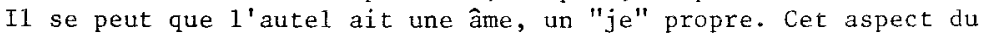
problème ne saurait être examiné ici. 


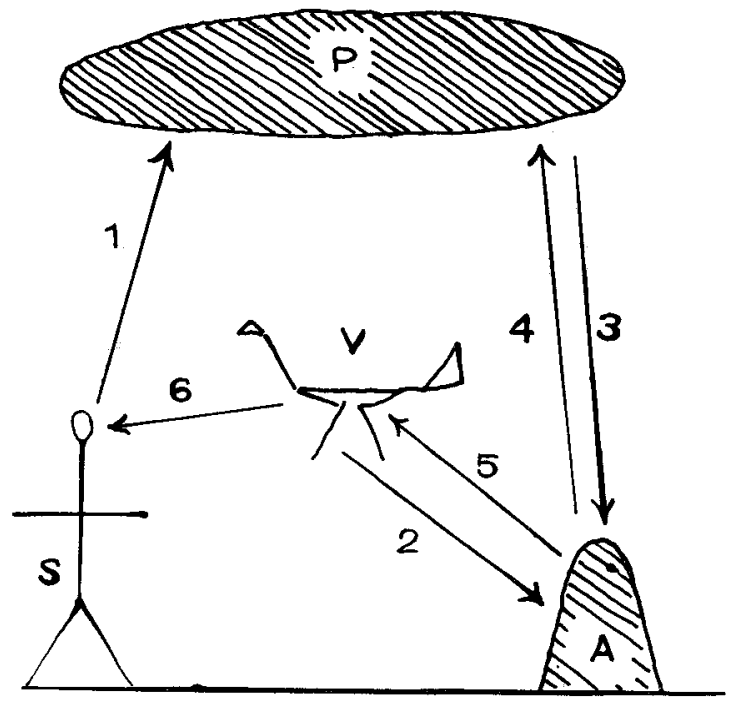

Fig. 38 -- Essai de représentation schématique du mécanisme du sacrifice sanglant dans le service ordinaire des puissances surnaturelles (Dogons des falaises nigériennes). 